\title{
Turkish Version of the Fear of COVID-19 Scale: Validity and reliability study for children and adolescents
}

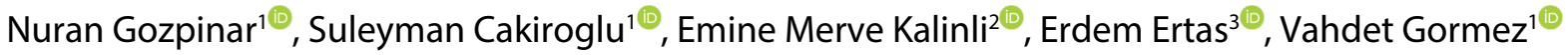 \\ 'Istanbul Medeniyet University, Goztepe Training and Research Hospital, Department of Child and Adolescent Psychiatry, \\ Istanbul - Turkey \\ ${ }^{2}$ Adiyaman Training and Research Hospital, Department of Child and Adolescent Psychiatry, Istanbul - Turkey \\ ${ }^{3}$ Mus State Hospital, Department of Child and Adolescent Psychiatry, Mus - Turkey
}

\begin{abstract}
Objective: The number of publications reporting anxiety and fear about the ongoing outbreak of coronavirus 2019 (COVID-19) continues to grow; however, the psychometric tools available to assess a Turkish population are insufficient to measure the relevant mental health outcomes. The purpose of this study was to examine the psychometric properties of the Turkish version of the Fear of COVID-19 Scale (FCV-19S) and to analyze the validity and reliability in children and adolescents.

Method: The study sample consisted of 381 children aged 10-18 years. Cronbach's alpha internal consistency analysis was used to evaluate the scale's reliability, and the criterion validity was assessed with the Revised Child Anxiety and Depression ScaleChild (RCADS-C) subscale scores. The construct validity of the scale was examined using exploratory and confirmatory factor analysis.

Results: The Cronbach's alpha internal consistency coefficient calculated to determine the scale's reliability was $a=0.88$. The corrected total item test correlation values of the items varied between 0.63 and 0.68 . Exploratory factor analysis determined that the factor load of the scale items was $0.73-0.77$ and that there was only one factor with an eigenvalue $>1$. Confirmatory factor analysis indicated that the fit indices were acceptable.

Conclusion: These findings show that the Turkish version of the FCV-19S is a valid and reliable measurement tool for use with children and adolescents.
\end{abstract}

Keywords: COVID-19, fear, reliability, scale, validity

\section{INTRODUCTION}

Coronavirus 2019 (COVID-19) is a highly contagious disease caused by severe acute respiratory syndrome coronavirus-2 (1). The COVID-19 outbreak started in Wuhan, China, in December 2019 and soon affected the entire world (2). On March 11, 2020, the World Health Organization (WHO) declared the COVID-19 outbreak a pandemic due to the worrisome spread. According to recent WHO data, the total number of cases has surpassed 100 million, and the number of deaths has exceeded 2 million (3). The number of

How to cite this article: Gozpinar N, Cakiroglu S, Kalinli EM, Ertas E, Gormez V. Turkish Version of the Fear of COVID-19 Scale: Validity and reliability study for children and adolescents. Dusunen Adam The Journal of Psychiatry and Neurological Sciences 2021;34:32-40.

Correspondence: Suleyman Cakiroglu, Istanbul Medeniyet University, Goztepe Training and Research Hospital, Department of Child and Adolescent Psychiatry, Istanbul - Turkey

E-mail: suleyman5586@gmail.com

Received: September 10, 2020; Revised: December 08, 2020; Accepted: February 08, 2021 
COVID-19-positive cases has been increasing in Turkey, as in the rest of the world. As of December 10, 2020, the official number of cases in Turkey had exceeded 1.7 million, and the death toll was more than 15.000 (4).

Fear has been defined as an emotional response triggered by "real," "external," "known," or "objective" stimuli that lead to defensive or escape behaviors. It represents an alarm that occurs when a dangerous event is perceived as directly threatening, serves to protect the individual from potentially adverse events, and elicits physical and cognitive responses (5). Anxiety can emerge as a response to an unknown threat or an internal conflict $(6,7)$. Thus, the unclear source of the anxiety can lead to a state of hopelessness and a feeling of a lack of control focused on possible future threats.

The high rate of infection and contagion, relatively high mortality rate, and uncertainty about the course of the pandemic have led to more and more reports of COVID-19-related fear and anxiety (8-10). Infectious diseases, by their very nature, can cause a level of fear that impairs functionality. The fear is typically directly associated with the disease's transmission rate and its environment (fast and invisible), morbidity and mortality, and often with unfounded and frightening posts about the disease on social media (11). The emergence of a new disease, the lack of effective treatment, uncertainty about how long the outbreak will last, how many people will be infected worldwide, and if or when people can return to normal life are factors that exacerbate the severity of fear and anxiety (12). Although it is very natural for individuals to be afraid of becoming infected with a virus with a high mortality rate, prejudices in society can cause fear and anxiety to reach a level that is excessive (13). The easy aerosol transmission of the virus that causes COVID-19 and its pandemic nature have produced stigmatization, feelings of guilt, and other related issues (14). The current approach to COVID-19 worldwide is primarily focused on infection control, treatment, and eventually, vaccination $(15,16)$. The psychological effects of the epidemic and methods of intervention have not been fully evaluated or addressed. In order for society to completely recover from COVID-19, all aspects of the outbreak must be examined with a biopsychosocial approach (17). Fear and anxiety can appropriately mediate individual actions; however, excessive fear and anxiety can further increase the damaging effects of the presence of the disease by reducing the capacity of individuals to reason and to react appropriately. It has been reported that fear of disease and death associated with COVID-19 has led to inappropriate behavior, such as unnecessary medical care, excessive protection against the virus, and stockpiling of some items (13). A persistent fear of disease and death can create a chronic state of over-arousal (vigilance) against potential threats and lay the groundwork for generalized anxiety about future-oriented, common, and non-threatening situations $(18,19)$. Anxiety can also trigger depressive symptoms through preoccupation, negative expectations, and general pessimism $(20,21)$. Studies have demonstrated a positive correlation between fear and anxiety levels associated with COVID-19 and symptoms of anxiety and depression $(22,23)$. The evidence of negative effects on individual mental health and well-being during the pandemic period have exposed the importance of an accurate means to determine the individual level of fear and anxiety associated with COVID-19 and intervening when necessary.

The most important reason for the lack of a suitable, comprehensive approach to fears of COVID-19 has been the inadequacy of existing psychometric tools. Ahorsu et al. (17) developed the Fear of COVID-19 Scale (FCV-19S) to fulfill this need for a new disease in a study with 717 participants. The unidimensional instrument uses a 5-point Likert scale consisting of 7 items. In their study, the Perceived Vulnerability to Disease Scale, the Hospital Anxiety and Depression Scale, and the FCV-19S were administered to adults. The statistical analysis indicated that the FCV-19S was a valid and reliable assessment tool (17).

Bitan et al. (24) studied the psychometric properties of the Hebrew version of the FCV-19S in a sample of 649 individuals, $30.5 \%(n=195)$ of whom were male. The authors performed exploratory factor analysis using varimax rotation and reported that the factor load of the scale was $0.57-0.82$. The factor related to emotional fear reactions explained $53.71 \%$ of the total variance, while the second factor related to symptomatic expressions of fear explained $12.05 \%$ of the variance. A reliability analysis assessing both a unidimensional and a two-factor model indicated a Cronbach's alpha of 0.86 for the unidimensional model, 0.77 for Factor 1 and 0.80 for Factor 2. Reznik et al. (22) conducted an adaptation study using the translation and backtranslation method. The scale was administered to 850 participants from two Eastern European countries, Russia ( $\mathrm{n}=574,67.5 \%)$ and Belarus $(\mathrm{n}=276,32.5 \%)$, with a mean age of 34.8 years $(\mathrm{SD}=13)$, and the reliability was determined to be sufficient $(\alpha=0.81)$. Following the principal component analysis, varimax 
rotation was applied, and the analysis results also revealed a two-factor structure - physiological responses to COVID-19 (items 3,6, and 7) and emotional responses to COVID-19 (items 1, 2, 4, and 5) - in which the factor load was $0.57-0.84$ and explained about $51 \%$ and $47 \%$ of the total variance, respectively (22). The scale was also administered to 249 individuals in Italy: $92 \%$ of the participants were women, and the mean age of the group was 34.5 years $(\mathrm{SD}=12.21)$. The analysis supported a single-factor structure. The factor load was $0.69-0.90$ and indicated that the scale was a valid and reliable measurement tool $(\alpha=0.87)$ (25). In Bangladesh, an adaptation study was conducted with 8550 participants, $56 \%$ of whom were male, with an average age of 26.53 years ( $S D=9.09)$, and the results showed that the internal consistency level of the single-factor scale was acceptable $(\alpha=0.87)$ with a load of $0.72-0.80$ (26). Adaptation studies were also carried out in Saudi Arabia and Greece with the participation of 370 and 2970 adults, respectively, and yielded similar results: the factor load and Cronbach alpha level were found to be acceptable $(\alpha>0.85)(27,28)$.

The FCV-19S was previously adapted for Turkish adults over 18 years of age, and the psychometric properties were examined (29). Both the original Iranian study and the assessment of the version for adults supported the single-factor structure. The factor load was $0.50-0.81$ and $0.48-0.72$, respectively, and the Cronbach alpha level was 0.86 and 0.85 , respectively $(17,29)$. A review of the literature revealed no study examining the psychometric properties of the FCV-19S for children and adolescents. The aim of this study was to examine the psychometric properties of the Turkish version of the FCV-19S designed to evaluate the level of fear associated with the COVID-19 outbreak in a sample consisting of children and adolescents aged $10-18$ years.

\section{METHOD}

\section{Sample}

The research sample comprised students from grades 4-12 from various provinces in Turkey aged 10-18 years. Scale validity and reliability studies in the literature have recommended that the minimum sample size should be at least five individuals for each variable and a minimum of 300 participants for factor analysis (30). The construct validity of the scale was tested in this study with exploratory factor analysis (EFA) and confirmatory factor analysis (CFA). The easy sampling method was used to form a sample of 381 individuals.
Families with children aged 10-18 were contacted and informed about the study by teachers via social media platforms. The teachers then sent a link that has the online scale to families who enrolled in the study. The data were collected and analyzed after obtaining an electronic informed consent form from the children and their families.

\section{Data Collection Tools Sociodemographic Data Form}

The researchers created an information form to record the age and educational status of the students participating in the study.

\section{Revised Children's Anxiety and Depression Scale}

The Revised Children's Anxiety and Depression Scale (RCADS) was developed to screen for anxiety disorders and depression in children and adolescents as defined by the Diagnostic and Statistical Manual of Mental Disorders, fourth edition (31). The scale includes forms for the child (RCADS-C) and the parent (RCADS-P), and consists of six subscales and 47 items: generalized anxiety disorder (6 items), separation anxiety disorder (7 items), panic disorder (9 items), obsessivecompulsive disorder (6 items), social anxiety disorder (9 items), and major depressive disorder (10 items). Each item is scored between 0 and 3 ( $0=$ never, $1=$ sometimes, 2 =often, 3 =always). The validity and reliability study of the Turkish child and parent forms was performed by Görmez et al. (31). The Cronbach's alpha coefficient was determined to be 0.95 .

\section{Fear of COVID 19 Scale}

The first FCV-19S was developed by Ahorsu et al. (17) in 2020 to assess coronavirus-related fear. The original scale was administered in Persian or Farsi and consists of seven items with a five-point Likert type and a single dimension; there is no cutoff value. The total score can be 7-35. A higher total score indicates a greater level of anxiety. Validity and reliability for evaluating coronavirus-induced fears in adults over the age of 18 was established. The Cronbach alpha coefficient was found to be 0.82 (17). A validity and reliability study of the scale for the Turkish adult population was conducted by Haktanır et al. (32) and it was found to be a valid and reliable measurement tool.

\section{Translation of the Scale and Ethical Issues}

The authors of the original scale were contacted and granted permission for a validity and reliability study of the scale for use with children and adolescents. 
In the first stage, the scale's language validity was evaluated, and the original scale was translated from English to Turkish by the researchers. An independent linguist and professional translator did the translation. The research team evaluated the results and created the first draft. The form was then translated back into English by a different professional translator. The backtranslated form was compared with the original form by an independent researcher whose native language is English. The research team finalized the scale according to the suggestions offered. The comprehensibility of the scale items was evaluated with a 10-person pilot application, and it was determined that no changes were necessary.

In the second stage, the scale was evaluated in terms of content validity. One of the most widely used techniques to evaluate content validity is the Lawshe technique (33). The opinions of 10 experts in the fields of child psychiatry, English language, Turkish language, and assessment and evaluation were obtained using the Lawshe technique, and the content validity of the items and the content validity index of the scale were calculated.

Authorization to conduct this study was obtained from the Ministry of Health General Directorate of Health Services and the ethics committee of Istanbul Medeniyet University, Göztepe Training and Research Hospital (2020/0322).

\section{Statistical Analysis}

The data were statistically analyzed using the IBM SPSS Statistics for Windows, Version 24.0 (IBM Corp., Armonk, NY, USA) and AMOS 22 (IBM Corp., Armonk, NY, USA). Descriptive statistics (number, percentage, average, SD) were calculated, and the content validity index was applied to quantitatively calculate the content validity. The reliability analysis included the Cronbach alpha coefficient for internal consistency, Pearson moments multiplication coefficient analysis for item-total correlation, and CFA and EFA for validity analysis. As a result of CFA, model fit indexes (chi-square to degree of freedom ratio, goodness-of-fit index, adjusted goodness-of-fit index, comparative fit index, root-mean-square error of approximation, and standardized root-mean-square residual) were used to evaluate the original scale model fit. Factors with an eigenvalue of $\geq 1$ were evaluated according to EFA principal components analysis. The acceptance level for factor load values in EFA was set at 0.400 . The suitability of sample size was evaluated with the Kaiser-Meyer-Olkin (KMO) test, and the compatibility of the correlation matrix for factor analysis was evaluated with the Bartlett test of sphericity. The reliability of the scale was examined using internal consistency analysis (34).

\section{RESULTS}

\section{Sociodemographic Characteristics}

A total of 381 children and adolescents aged 10-18 participated in the study. Of the group, $50.6 \%(n=192)$ were boys, and $49.4 \%(n=189)$ were girls. The age distribution was $107(28.1 \%)$ aged $10-14$ and 274 (71.9\%) aged $15-18$, with a mean age of $15.36 \pm 2.36$ years. The participants were students from 4 th grade (primary school) through $12^{\text {th }}$ grade (high school).

\section{Content Validity}

The evaluation of the content validity index based on expert opinions was 0.91 , with a validity rate for the scale items of $0.80-1.00$. The findings indicated that the content validity of the scale was high.

\section{Construct Validity}

Table 1 illustrates the independent group t-test results for each item and the item-total test correlation. The minimum required value for the item-total test correlation to be sufficient was determined to be 0.30

Table 1: Item analysis results 1

\begin{tabular}{lcccc} 
& t & $\begin{array}{c}\mathbf{p} \\
\text { (Low 27\%-High 27\%) }\end{array}$ & $\begin{array}{c}\text { Corrected item-total } \\
\text { Cronbach's alpha value } \\
\text { (Low 27\%-High 27\%) }\end{array}$ & $\begin{array}{c}\text { correlation coefficients } \\
\text { when the item is eliminated }\end{array}$ \\
\hline Item 1 & -20.635 & 0.001 & 0.68 & 0.86 \\
Item 2 & -21.098 & 0.001 & 0.63 & 0.86 \\
Item 3 & -16.118 & 0.001 & 0.65 & 0.86 \\
Item 4 & -23.904 & 0.001 & 0.67 & 0.86 \\
Item 5 & -22.372 & 0.001 & 0.66 & 0.86 \\
Item 6 & -14.800 & 0.001 & 0.67 & 0.86 \\
Item 7 & -17.338 & 0.001 & 0.66 & 0.86 \\
\hline
\end{tabular}


(35). The corrected item-total test correlation values of the items were $0.63-0.68$. The raw scores were ranked in descending order to determine the distinctiveness of the items in the scale. The mean group scores in the lower $27 \%$ and the upper $27 \%$ segments were compared with the independent group t-test. A statistically significant difference was observed between the lower and upper item score means.

As shown in Table 2, EFA examined the scale's factor structure. Before EFA was performed, a KMO test was conducted to test the compatibility for factorization, and the resulting KMO value was 0.886 . It was concluded that the sample size was "completely adequate" for factor analysis (36). Bartlett's sphericity test results indicated that the chi-squared value was significant $\left(\chi^{2}=1197.395 ; \mathrm{p}<0.01\right)$ and it was accepted that the data had a multivariate normal distribution.

Once the data were confirmed for factor analysis, EFA was performed using principal component analysis to examine the scale's factor structure. Only one factor had an eigenvalue $>1$. The contribution of this component to the total variance was $57.73 \%$. The factor load values were $0.73-0.77$ (Table 2 ).

Scale reliability was analyzed using internal consistency analysis, and the stability over time was examined with the test-retest method. As shown in Table 2, the Cronbach alpha value for the entire scale (7 items) was 0.88 (36). To determine the test-retest reliability, the scale was administered twice to 40 students aged 12-18 at an interval of 2 weeks. There was no statistically significant difference $(t=0.495 ; \mathrm{p}=0.528)$ between the total scores obtained from the first and second tests. A positive, versatile, and highly significant relationship $(\mathrm{r}=0.831 ; \mathrm{p}<0.001)$ was found among the total scores obtained.

In addition, a slope stability graph was prepared to assess the appropriate number of factors. The graph showed an accelerated decline in eigenvalue only after the first factor. The slope indicates the degree of contribution to the variance (37) (Fig. 1). Based on the EFA, it was decided that a single factor was appropriate.

CFA was used to examine the construct validity of the scale. Due to the normal distribution of the data, maximum likelihood was used as the estimation method (38). Factor analysis results suggested modifications to increase the GFI. The error variances of item 1 and item 2 as well as item 6 and item 7 were combined. The fit indices were found to be acceptable

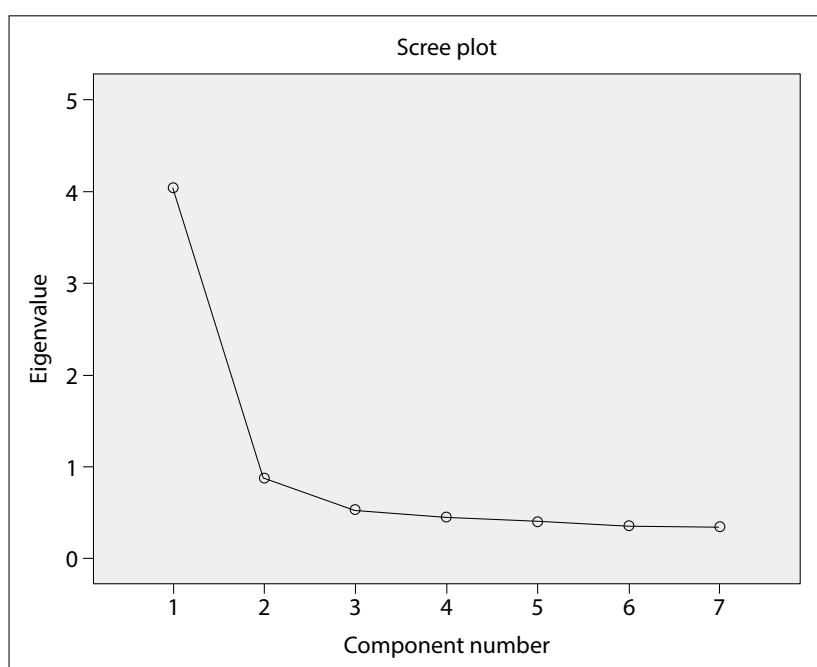

Figure 1. Slope stability graph.

Table 2: Exploratory factor analysis results of the COVID-19 fear scale

\begin{tabular}{lcccc} 
& Eigenvalue & $\begin{array}{c}\text { Explained variance } \\
\text { (\%) }\end{array}$ & Factor load & $\begin{array}{c}\text { Common variance } \\
\text { Anti-image }\end{array}$ \\
\hline F1 (a=0.88) & 4.04 & 57.73 & & \\
Item 1 & & 0.771 & 0.585 & 0.864 \\
Item 2 & 0.769 & 0.531 & 0.858 \\
Item 3 & 0.768 & 0.578 & 0.896 \\
Item 4 & 0.765 & 0.591 & 0.915 \\
Item 5 & 0.760 & 0.573 & 0.921 \\
Item 6 & 0.757 & 0.594 & 0.873 \\
Item 7 & 0.728 & 0.589 & 0.881 \\
Kaiser-Mayer-Olkin measure & & & & 0.886 \\
of sample adequacy & & & & \\
Bartlett test & & & & 1197.395 \\
& $\chi^{2}$ & & & 21 \\
\hline
\end{tabular}


Table 3: Confirmatory factor analysis fit indices for fear of COVID-19 after modifications

\begin{tabular}{lccccccccc} 
& RMSEA & NFI & CFI & IFI & GFI & AGFI & CMIN & CMIN/sd & RMR \\
\hline Before modification & 0.157 & 0.888 & 0.897 & 0.898 & 0.882 & 0.764 & 142.698 & 10.193 & 0.082 \\
After the first modification & 0.115 & 0.940 & 0.949 & 0.949 & 0.934 & 0.859 & 76.823 & 0.074 & 0.515 \\
After the second modification & 0.097 & 0.957 & 0.966 & 0.967 & 0.957 & 0.900 & 54.528 & 0.55 & 0.415 \\
\hline
\end{tabular}

AGFI: Adjusted goodness-of-fit index, CFI: Comparative fit index, CMIN: The Likelihood Ratio Chi-Square Test, GFI: Goodness-of-fit index, df: degrees of freedom, IFI: Incremental fit index, NFI: Normed fit index, RMR: Root-mean-square residual, RMSEA: Root-mean-square error of approximation, SRMR: Standardized rootmean-square residual

Table 4: Fear scale attitude results

COVID-19 Fear Scale

Item 1

Item 3

Item 4

Item 5

Item 6

Item 7

Total
Item 2

\begin{tabular}{ccc} 
& Min-Max & Mean \pm SD \\
\hline I am most afraid of coronavirus & $1-5$ & $3.25 \pm 1.15$ \\
It makes me uncomfortable to think about coronavirus. & $1-5$ & $3.45 \pm 1.27$ \\
My hands become clammy when I think about coronavirus. & $1-5$ & $2.03 \pm 1.09$ \\
I am afraid of dying due to coronavirus. & $1-5$ & $3.04 \pm 1.32$ \\
When watching news or stories about coronavirus on social media, & $1-5$ & $3.11 \pm 1.28$ \\
I become nervous or anxious. & $1-5$ & $1.87 \pm 1.04$ \\
I cannot sleep because I'm worrying about coronavirus. & $1-5$ & $2.15 \pm 1.17$ \\
y heart races or palpitates when I think about getting coronavirus. & $7-35$ & $18.90 \pm 6.32$ \\
\hline
\end{tabular}

(34). The gradual change in the fit indices after the modifications is shown in Table 3.

After the appropriate matrix was created, a path diagram was drawn to observe the model's variables and factor loads to demonstrate the outputs of the model (35). The standardized factor loads of the scale items were $0.68-0.74$. The path diagram and factor loads of the scale are shown in Figure 2.

\section{Criterion Validity of the COVID-19 Fear Scale and Mean Scale Item Scores}

The mean and SD, as well as the minimum and maximum FCV-19S scores are shown in Table 4. The

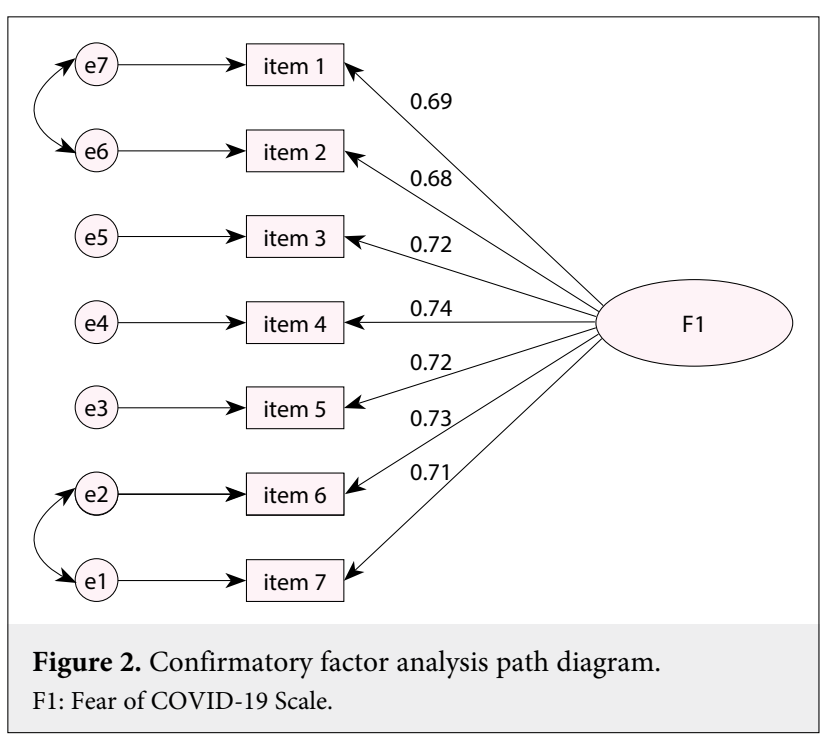

criterion validity was assessed according to the relationship with the RCADS-C sub-dimensions. The results in Table 5 demonstrate that the relationship between the FCV-19S total score and RCADS-C subdimensions was positive and significant.

\section{DISCUSSION}

This study shows that the Turkish version of the FCV$19 S$ for children had a higher reliability coefficient than the original, and acceptable internal consistency. Reliability assessment reveals the consistency of the questions, the uniformity, and acceptable measurement $(36,37)$. The scale items should have a certain conceptual structure, and the measurement should reflect the same structure $(36,37)$. Internal consistency analysis examines whether the items consistently measure the conceptual structure with a single measurement in a single session. The Cronbach alpha coefficient is a value that indicates internal consistency in Likert-type scales. This value indicates whether the items are associated with the subject to be measured. The Cronbach's alpha coefficient should be as close to 1 as possible $(36,37)$. The Cronbach's alpha reliability coefficient of FCV-19S developed by Ahorsu et al. (17), was 0.82. In our study, the Cronbach alpha reliability coefficient of the Turkish form was 0.88 . Cronbach's alpha values ranging of $0.81-0.87$ have been reported in adaptation studies conducted with adult participants $(22,24,25,27-29)$. In this study conducted 


\begin{tabular}{lccccccc}
\multicolumn{7}{l}{ Table 5: COVID-19 fear scale and association with RCADS-C } \\
\cline { 2 - 7 } & Test & RCADS-SAD & RCADS-SP & RCADS-OCD & RCADS-PD & RCADS-CAD & RCADS-MDD \\
\hline Item 1 & $\mathrm{r}$ & 0.337 & 0.253 & 0.299 & 0.291 & 0.363 & 0.243 \\
& $\mathrm{p}$ & $<.001$ & $<0.001$ & $<0.001$ & $<0.001$ & $<0.001$ & $<0.001$ \\
Item 2 & $\mathrm{r}$ & 0.322 & 0.255 & 0.284 & 0.313 & 0.405 & 0.300 \\
& $\mathrm{p}$ & $<0.001$ & $<0.001$ & $<0.001$ & $<0.001$ & $<0.001$ & $<0.001$ \\
Item 3 & $\mathrm{r}$ & 0.391 & 0.326 & 0.362 & 0.414 & 0.444 & 0.315 \\
& $\mathrm{p}$ & $<0.001$ & $<0.001$ & $<0.001$ & $<0.001$ & $<0.001$ & $<0.001$ \\
Item 4 & $\mathrm{r}$ & 0.371 & 0.370 & 0.384 & 0.387 & 0.480 & 0.320 \\
& $\mathrm{p}$ & $<0.001$ & $<0.001$ & $<0.001$ & $<0.001$ & $<0.001$ & $<0.001$ \\
Item 5 & $\mathrm{r}$ & 0.352 & 0.316 & 0.354 & 0.362 & 0.423 & 0.354 \\
& $\mathrm{p}$ & $<0.001$ & $<0.001$ & $<0.001$ & $<0.001$ & $<0.001$ & $<0.001$ \\
Item 6 & $\mathrm{r}$ & 0.400 & 0.320 & 0.376 & 0.466 & 0.463 & 0.413 \\
& $\mathrm{p}$ & $<0.001$ & $<0.001$ & $<0.001$ & $<0.001$ & $<0.001$ & $<0.001$ \\
Item 7 & $\mathrm{r}$ & 0.466 & 0.379 & 0.415 & 0.547 & 0.501 & 0.427 \\
& $\mathrm{p}$ & $<0.001$ & $<0.001$ & $<0.001$ & $<0.001$ & $<0.001$ & $<0.001$ \\
FCV-19S total score & $\mathrm{r}$ & 0.494 & 0.418 & 0.465 & 0.520 & 0.581 & 0.445 \\
& $\mathrm{p}$ & $<0.001$ & $<0.001$ & $<0.001$ & $<0.001$ & $<0.001$ & $<0.001$
\end{tabular}

CAD: Common anxiety disorder, FCV-19S: Fear of COVID-19 Scale, MDD: Major depressive disorder, OCD: Obsessive-compulsive disorder, PD: Panic disorder, RCADS: Revised Child Anxiety and Depression Scale, SAD: Separation anxiety disorder, SP: Social phobia

with children and adolescents, the reliability coefficient of the Turkish FCV-19S was found to be similar to the results for adults reported in the literature (17). The main purpose of item-total score analysis, or item reliability, is to determine each item's contribution to the total score of the scale and to what extent it is associated with the whole scale $(36,39)$. In this analysis, the variance of each item was compared with the scale's total score variance, and the association between them was examined with Pearson's correlation analysis. Reliability increases as the $r$ value approaches $1(36,37)$. In the original form of the scale, the item-total correlation values were $0.47-0.56$ (17). The reliability analysis of the Turkish FCV-19S item-total score correlations revealed that the correlation coefficients of the scale items was 0.63-0.68 and the results indicated that the scores of all of the items on the scale were statistically significant and highly correlated with the scale total score. Comparison of the mean item scores of the $27 \%$ lower and $27 \%$ upper segments revealed a statistically significant difference. The Turkish form of the scale successfully discriminated measurement of the desired element.

Validity is the ability to measure the intended variable accurately and precisely (39). Construct validity was used to evaluate the extent to which the scale items were associated with latent variables to be measured and the extent to which the association between the variables fits the established model (34). The fact that the EFA performed to determine the factor structure of the Turkish scale revealed only a single factor with an eigenvalue $>1$ and the contribution to the total variance was $57.73 \%$, indicates that the Turkish version is similar to the original scale (17). Adaptation studies conducted in different languages have yielded factor loads of 0.57 0.90 , while the results for the Turkish version were 0.73-0.77. The factor loads were above the accepted value of 0.40 , and the factor loads of the third, sixth, and seventh items were higher than the factor loads obtained from the Turkish adaptation study with adults $(16,21,22)$. CFA was performed to test the compatibility of the model obtained after EFA (38). Model compatibility in the study was evaluated with fit indices. Incorporation of the modification suggestions generated in the analysis recommending combining the error variance of items 1 and 2 and items 6 and 7 led to fit indices of an acceptable level (Table 3) $(34,39)$.

In the original FCV-19S, criterion validity was supported by the positive correlation of the scale total scores with the subscale scores of the Perceived Vulnerability to Disease Scale and the Hospital Anxiety and Depression Scale (17). In this study, criterion validity was demonstrated by the presence of a significant positive correlation between the FCV-19S children subscale scores and the total scores of the Turkish version of the FCV-19S. Examination of the association between the FCV-19S total score and the 
FCV-19S children subscale scores revealed that it was associated with the RCADS-PD $(\mathrm{r}=0.520 ; \mathrm{p}<0.001)$ and the RCADS-CAD $(r=0.581 ; \mathrm{p}<0.001)$ These results are consistent with literature data showing that the FCV$19 \mathrm{~S}$ is highly associated with anxiety symptoms $(17,23,40)$.

These results support the construct validity of the FCV-19S and show that this scale is a valid tool that can be used in children and adolescents.

Fear and anxiety are among the most common mental symptoms experienced by children during a pandemic. One of the study's strengths is that we have demonstrated that the scale is a valid and reliable measurement tool that can be used to identify children and adolescents with a high anxiety level due to the pandemic before the development of psychopathology. This is the first study to examine the psychometric properties of the FCV-19S in children and adolescents.

Some limitations of this research include the lack of face-to-face interviews, the inability to identify participants with an existing psychopathology, the possibility of response bias and reliability problems. The sociodemographic data form was very short due to a concern that if it was long, it could take too much time and reduce the answers' reliability.

The COVID-19 outbreak will likely have negative effects on the mental health of much of the population, even if it is not yet very visible today. The fact that the pandemic causes unexpected losses and threatens the health of virtually the whole world can create a sense of helplessness and lead to intense fear and anxiety. It is important to detect these symptoms before the development of psychopathology and to intervene as necessary, especially for children and adolescents, who are a more sensitive population. The FCV-19S is a valid and reliable measurement tool to assess COVID-19induced fears in Turkish children aged 10-18 and administration of this scale will facilitate the detection of those at risk and enable early intervention. It could be a valuable means to mediate effects resulting from the pandemic and improve mental health.

\begin{tabular}{|c|c|c|}
\hline \multicolumn{2}{|c|}{ Contribution Categories } & Author Initials \\
\hline \multirow{3}{*}{ Category 1} & Concept/Design & N.G., S.C. \\
\hline & Data acquisition & E.M.K., E.E. \\
\hline & Data analysis/Interpretation & S.C. \\
\hline \multirow{2}{*}{ Category 2} & Drafting manuscript & N.G., V.G. \\
\hline & Critical revision of manuscript & V.G \\
\hline Category 3 & Final approval and accountability & V.G. \\
\hline \multirow{2}{*}{ Other } & Technical or material support & $\mathrm{N} / \mathrm{A}$ \\
\hline & Supervision & $\mathrm{N} / \mathrm{A}$ \\
\hline
\end{tabular}

Ethics Committee Approval: Ethics committee approval was received from the Ethics committee of Istanbul Medeniyet University Göztepe Training and Research Hospital. (Date: 03.06.2020, Number: 2020/0322)

Informed Consent: Consent of the patient has been obtained.

Peer-review: Externally peer-reviewed.

Conflict of Interest: There is no author conflict.

Financial Disclosure: There is no financial support.

\section{REFERENCES}

1. Yan S, Song X, Lin F, Zhu H, Wang X, Li M, et al. Clinical characteristics of coronavirus disease 2019 in Hainan, China. medRxiv 2020. doi:10.1101/2020.03.19.20038539. [Epub Ahead of Print]

2. Bao Y, Sun Y, Meng S, Shi J, Lu L. 2019-nCoV epidemic: address mental health care to empower society. Lancet 2020; 395:e3738.

3. Cash JC, Glass CA, Mullen J. Coronavirus Disease (COVID19). Family Practice Guidelines. Springer Publishing Company; 2020.

4. Ministry of Health. COVID-19 information page. https:// covid19.saglik.gov.tr/. Accessed December 1, 2020.

5. Barlow DH. Unraveling the mysteries of anxiety and its disorders from the perspective of emotion theory. Am Psychol 2000; $55: 1247-1263$

6. Steimer T. The biology of fear- and anxiety-related behaviors. Dialogues Clin Neurosci 2002; 4:231-249.

7. Nathanson DL. The psychology of emotion: Theories of emotion in perspective. Fourh ed., Am J Psychiatry 1997; 154:1616-1617.

8. Jiao WY, Wang LN, Liu J, Fang SF, Jiao FY, Pettoello-Mantovani $\mathrm{M}$, et al. Behavioral and emotional disorders in children during the COVID-19 Epidemic. J Pediatr 2020; 221:264-266.e1.

9. Yang Y, Li W, Zhang Q, Zhang L, Cheung T, Xiang YT. Mental health services for older adults in China during the COVID-19 outbreak. Lancet Psychiatry 2020; 7:e19.

10. Xiao C. A novel approach of consultation on 2019 novel coronavirus (COVID-19)-related psychological and mental problems: structured letter therapy. Psychiatry Investig 2020; 17:175-176.

11. Pappas G, Kiriaze IJ, Giannakis P, Falagas ME. Psychosocial consequences of infectious diseases. Clin Microbiol Infect 2009; 15:743-747.

12. Zandifar A, Badrfam R. Iranian mental health during the COVID-19 epidemic. Asian J Psychiatr 2020; 51:101990.

13. Lin C-Y. Social reaction toward the 2019 novel coronavirus (COVID-19). Soc Heal Behav 2020; 3:1-2.

14. Huang C, Wang Y, Li X, Ren L, Zhao J, Hu Y, et al. Clinical features of patients infected with 2019 novel coronavirus in Wuhan, China. Lancet 2020; 395:497-506. 
15. Wang C, Horby PW, Hayden FG, Gao GF. A novel coronavirus outbreak of global health concern. Lancet 2020; 395:470-473.

16. Cao W, Fang Z, Hou G, Han M, Xu X, Dong J, et al. The psychological impact of the COVID-19 epidemic on college students in China. Psychiatry Res 2020; 287:112934.

17. Ahorsu DK, Lin CY, Imani V, Saffari M, Griffiths MD, Pakpour AH. The fear of COVID-19 scale: development and initial validation. Int J Ment Health Addict 2020; 1-9. doi: 10.1007/ s11469-020-00270-8. [Epub Ahead of Print]

18. McNally RJ. Anxiety and its disorders: The nature and treatment of anxiety and panic, Second ed., Am J Psychiatry 2002; 159:14531453

19. Harding KJ, Skritskaya N, Doherty E, Fallon BA. Advances in understanding illness anxiety. Curr Psychiatry Rep 2008; 10:311317.

20. Starr LR, Davila J. Responding to Anxiety with Rumination and Hopelessness: Mechanism of Anxiety-Depression Symptom Co-Occurrence? Cognit Ther Res 2012; 36:321-337.

21. Konick LC, Gutierrez PM. Testing a model of suicide ideation in college students. Suicide Life Threat Behav 2005; 35:181-192.

22. Reznik A, Gritsenko V, Konstantinov V, Khamenka N, Isralowitz R. COVID-19 fear in eastern europe: Validation of the fear of COVID-19 scale. Int J Ment Health Addict 2020. doi: 10.1007/ s11469-020-00283-3. [Epub Ahead of Print]

23. Lee SA, Mathis AA, Jobe MC, Pappalardo EA. Clinically significant fear and anxiety of COVID-19: A psychometric examination of the Coronavirus Anxiety Scale. Psychiatry Res 2020; 290:113112.

24. Tzur Bitan D, Grossman-Giron A, Bloch Y, Mayer Y, Shiffman N, Mendlovic S. Fear of COVID-19 scale: Psychometric characteristics, reliability and validity in the Israeli population. Psychiatry Res 2020; 289:113100.

25. Soraci P, Ferrari A, Abbiati FA, Del Fante E, De Pace R, Urso A, et al. Validation and psychometric evaluation of the Italian version of the Fear of COVID-19 Scale. Int J Ment Health Addict 2020; 1-10. doi: 10.1007/s11469-020-00277-1. [Epub Ahead of Print]

26. Griffiths MD, Pakpour AH, Mamun MA. Correction to: Psychometric validation of the Bangla Fear of COVID-19 Scale: Confirmatory factor analysis and rasch analysis. Int J Ment Health Addict 2020. doi: 10.1007/s11469-020-00399-6. [Epub Ahead of Print]

27. Alyami M, Henning M, Kr.geloh CU, Alyami H. Psychometric Evaluation of the Arabic Version of the Fear of COVID-19 Scale.
Int J Ment Health Addict 2020; 1-15. doi: 10.1007/s11469-02000316-x. [Epub Ahead of Print]

28. Tsipropoulou V, Nikopoulou VA, Holeva V, Nasika Z, Diakogiannis I, Sakka S, et al. Psychometric properties of the Greek version of FCV-19S. Int J Ment Health Addict 2020; 1-10. doi: 10.1007/s11469-020-00319-8. [Epub Ahead of Print]

29. Satici B, Gocet-Tekin E, Deniz ME, Satici SA. Adaptation of the Fear of COVID-19 Scale: Its association with psychological distress and life satisfaction in Turkey. Int J Ment Health Addict 2020; 1-9. doi: 10.1007/s11469-020-00294-0. [Epub Ahead of Print]

30. Tabachnick BG, Fidell LS. Using Multivariate Statistics. Fifth ed, Boston: Pearson Allyn and Bacon, 2007; 980.

31. Gormez V, Kilincaslan A, Orengul AC, Ebesutani C, Kaya I, Ceri $\mathrm{V}$, et al. Psychometric properties of the Turkish version of the Revised Child Anxiety and Depression Scale - Child Version in a clinical sample. J Clin Psychopharmacol 2017; 27:84-92.

32. Haktanir A, Seki T, Dilmaç B. Adaptation and evaluation of Turkish version of the fear of COVID-19 Scale. Death Studies 2020. doi: 10.1080/07481187.2020.1773026 [Epub Ahead of Print]

33. Lawshe $\mathrm{CH}$. A quantitative approach to content validity. Pers Psychol 1975; 28:563-575.

34. Koyuncu I, Kilic AF. The use of exploratory and confirmatory factor analyses: a document analysis. Education and Science 2019; 44: 361-388.

35. Kline RB. Principles and Practice of Structural Equation Modeling. Fourth ed., New York: Guilford Publications, 2016; $1-534$.

36. Balci A. Research Methods, Techniques and Principles in Social Sciences. Fourteenth ed., Ankara: Pegem Akademi Yayincilik, 2020; $1-420$.

37. Buyukozturk S, Akgun OE, Karadeniz S, Demirel F, Cakmak EK. Scientific Research Methods in Education. Twenty-eighth ed., Ankara: Pegem Akademi Yayincilik, 2020; 1-392.

38. Capık C, Gozum S, Aksayan S. Cross-cultural scale adaptation stages, language and culture adaptation: An updated guideline. Florance Nightingale J Nurs 2018; 26:199-210.

39. Sencan H. Reliability and Validity in Social and Behavioral Measurements. First ed., Ankara: Seckin Yayinevi, 2005; 1-867.

40. Rossi A, Panzeri A, Pietrabissa G, Manzoni GM, Castelnuovo G, Mannarini S. The anxiety-buffer hypothesis in the time of COVID19: when self-esteem protects from the impact of loneliness and fear on anxiety and depression. Front Psychol 2020; 11:2177. 